\title{
Evolution of the Plasticity of Some Low Carbon Steels, Subjected to Directed Cooling from High-temperature
}

\author{
CARMEN PENELOPI PAPADATU ${ }^{1}$, IOAN GABRIEL SANDU ${ }^{2}$, MARIAN BORDEI ${ }^{1}$, ANDREI VICTOR SANDU ${ }^{2,3 *}$, \\ ${ }^{1}$ Dunarea de Jos University of Galati, Faculty of Engineering, 111 Domneasca Str.,Galati, Romania \\ ${ }^{2}$ Gheorghe Asachi Technical University of Iasi, Faculty of Materials Science \& Engineering, 61A D. Mangeron Blvd., 700050, Iasi \\ Romania \\ ${ }^{3}$ Romanian Inventors Forum, 3 Sf. Petru Movila St., BI. L11, Sc. A., III/3, 700089, Iasi, Romania
}

\begin{abstract}
An important influence factor for the plasticity of the low carbon steels is the cooling speed value after heating treatment. It is important to be chooses the optimal cooling regime for these materials because the steels have been laminated at high temperature or, the steels have been heated at high temperature after lamination process. There were considered two groups of samples of two low carbon steels, each group had eight samples. Three different mediums for directing of the cooling process were considered and the properties of the steels have been modified. After an experimental program, the values obtained were used to determine the variation between these variables corresponding to two kinds of steels (coded: Steel 1 and Steel 2).
\end{abstract}

Keywords: steel; plasticity; monitoring; directed cooling; correlation; statistical model

The metallurgy and processing of advanced highstrength steels is well known, but is somewhat different compared to conventional steels. All these steels are produced by controlling the cooling rate after hot rolling at high temperature on run-out table or cold rolling (in annealing furnace). A special attention can be made on higher loads during deformation [1, 2], even these kind of steels do not brings new problems.

In the Literature, the group of steels meeting very high automotive requirements refers to the newer type called Advanced High Strength Steels (AHSS), which usually comprises Dual Phase (DP), Transformation Induced Plasticity (TRIP), Complex Phase (CP) and Martensitic Steels (MS) [2]. The paper focuses on directed fast cooled steels strips for automotive application after hot laminated process.

Microstructural control of metallic materials, such as the steels for example, during hot laminating (rolling) is an important key during the thermo-mechanical processing since it allows to control the final microstructure and in turn the desired mechanical properties of the alloys such as plasticity, for example [3]. Dynamic recrystallization (DRX) is the most important mechanism to control the microstructure of the steels, which can realizes the refinement of microstructure and the flow stress reduction. Understanding of the DRX behavior in the hot working or rolling of alloys (steels) will be helpful to determine the optimal processing parameters [4].

If we study the literature [ $1,5-21]$ for steels with $0.1 \% \mathrm{C}$, $0.48 \% \mathrm{Mn}, 0.24 \% \mathrm{Si}$, the microstructural parameters which determine the mechanical properties of the steels are the sizes and the shape of pearlitic (P) and ferritic (F) grains which form its microstructure. Ferrite has a low mechanical strength but it has plastic properties. Cementite (Cem) in steels has a good hardness but it is fragile and can provoke cracks. Therefore, with the increasing of the carbon content, the hardness and the strength of the steels increase but the plasticity decreases. These types of steels, for some parts of machine building, for example, are used current without chemical treatments. The steels with low carbon have high plasticity properties below $550^{\circ} \mathrm{C}$ and the thermal stresses will not leads to the formation of cracks [1]. Damage in the case of materials represents the progressive or sudden deterioration of their mechanical strength which conducts to thermal or chemical effects $[1,5,6]$. It is important to know how it is possible to improve the properties of the steels [5]. For this case, it is necessary to find a causal relation between a technological parameter (the speed of cooling which depend on the cooling medium) and mechanical properties of the steel such as the plasticity, for example.

The aim of the paper is the study of plasticity of some low carbon steels, subjected to direct coolyng from hightemperature with different colling conditions.

\section{Experimental part}

There were considered three groups of samples of each kind of the steel and each group had eightsamples. Chemical composition of the steels were presented in table 1.

There were applied three cooling regimes $[1,5]$ : (1) cooling regime in normal conditions; (2) cooling regime in metallic box; (3) cooling in air flow (using a jet of cold air). The initial temperatures were: $\mathrm{Tl}=850^{\circ} \mathrm{C}$ (for the first batch of samples), $\mathrm{T} 2=900^{\circ} \mathrm{C}$ (for the second batch of samples), $\mathrm{T} 3=950^{\circ} \mathrm{C}$ (for the third batch of samples) and $\mathrm{T} 4=1000^{\circ} \mathrm{C}$ (for the last batch of samples). If the cooling mediums differ, the speeds of the cooling are different. In

\begin{tabular}{|c|c|c|c|c|c|c|}
\hline Steel grade & $\mathrm{C}(\%)$ & $\mathrm{Mn}(\%)$ & $\mathrm{Si}(\%)$ & $\mathrm{P}(\%)$ & $\mathrm{S}(\%)$ & $\mathrm{Al}(\%)$ \\
\hline Steel 1 Amount & 0.11 & 0.48 & 0.24 & 0.01 & 0.01 & 0.0038 \\
\hline Steel 2 Amount & 0.14 & 1.51 & 0.31 & $0.0 \overline{1}^{-}$ & 0.01 & 0.041 \\
\hline
\end{tabular}

CHEMICAL COMPOSITION OF THE STEELS

* email: euroinvent@yahoo.com 
case of cooling in jet of air, the speed of the cooling will be the highest. Tensile tests related to room temperature were carried out according to ASTM: E8M-11 standard [5, 22], while those related to elevated temperatures were carried out according to ASTM: E21-09 [1, 5, 23, 24]. Charpy impact tests for resilience determination were carried out according to ASTM: E23-07ael standard [25].The preparation of metallographic specimens was conducted according to ASTM E3-11 standard [1, 5, 26, 27]. All of mentioned standards can be found in Annual Book of ASTM Standards (2012) [1].

\section{Results and discussions}

In table 2 were presented the cooling speed values for each different cooling conditions and the evolution of some mechanical properties which corresponds to these cooling regimes applied to the steels.

Cooling Speed value(VR) - Average [ C/min] was calculated with the following relation:

$$
V R=\frac{t^{\prime}-t 0}{\Delta \tau},
$$

where:

$t^{\prime}=$ the initial temperature corresponding to each cooling regime, $\left[{ }^{\circ} \mathrm{C}\right]$;

$20^{\circ} \mathrm{C}$;

$\mathrm{t}_{\mathrm{f}}=$ the final temperature which was approximate to

$\Delta \tau=$ the cooling duration, [ $\min$.$] .$

In some cases, because the difference between the initial temperature and the final one, the behavior of the evolution of the cooling speed values was special, unexpected.

In figures 1 to 4 were presented the evolution of the mechanical properties versus the cooling speed and the initial temperature, depending on the cooling regimes [ 1 , 5], for both steels analyzed. In figures 1 a to $1 \mathrm{c}$ and respectively, 4a to 4c was represented the evolution of the hardness (HB) of the Steel 1 and respectively, the Steel 2 versus the initial temperatures (ti) and cooling speed (VR). In figures $2 a$ to $2 c$ and respectively, $5 a$ to $5 c$ were
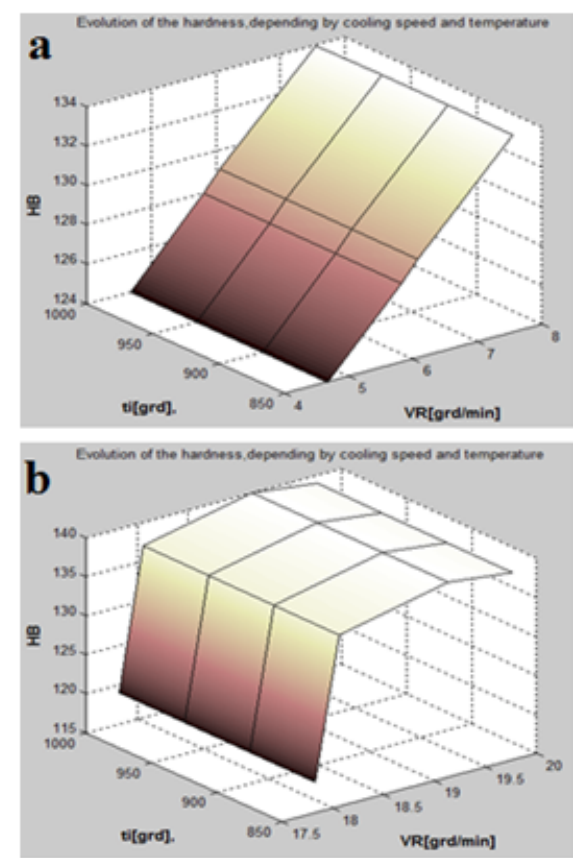

Fig. 1. The evolution of the Steel 1 hardness (HB) vs. cooling speed (VR) and temperature, for a - cooling in metallic box; $b$ - normal cooling conditions; c - cooling in jet of air

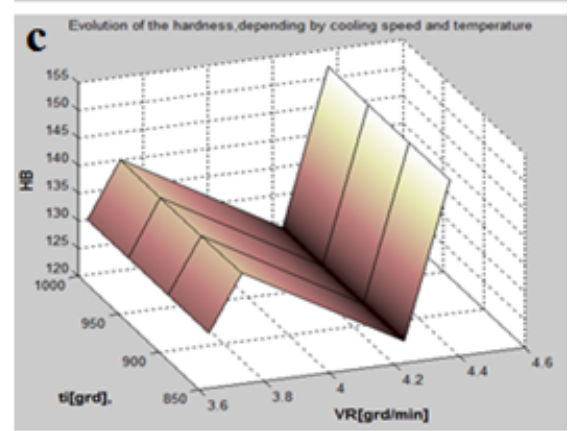

represented the evolutions of the plasticity characteristic, for example, the elongation at break (A5, [\%]) evolution versus the cooling speed (VR) and initial temperature (ti), for Steel 1 and Steel2. Graphics have been made using Matlab Program.

Table 2

THE INFLUENCE OF THE COOLING CONDITIONS ON THE PLASTICITY CHARACTERISTICS AND MECHANICAL PROPERTIES OF THE STEEL $[1,5]$

\begin{tabular}{|c|c|c|c|c|c|c|c|c|c|c|c|c|c|}
\hline \multirow[t]{3}{*}{$\begin{array}{l}\text { Cooling } \\
\text { conditions }\end{array}$} & \multirow[t]{3}{*}{$\begin{array}{c}\text { Initial } \\
\text { tempera } \\
\text { ture } \\
{\left[{ }^{\circ} \mathrm{C}\right]} \\
\end{array}$} & \multicolumn{2}{|c|}{$\begin{array}{c}\Psi[\%] \\
(\mathrm{Z})\end{array}$} & \multicolumn{2}{|c|}{$\mathrm{HB}$} & \multicolumn{2}{|c|}{$\begin{array}{c}\text { Cooling } \\
\text { Speed values } \\
\text { (VR)Average } \\
{\left[{ }^{\circ} \mathrm{C} / \text { min }\right]}\end{array}$} & \multicolumn{2}{|c|}{$\begin{array}{c}\mathrm{KV} \\
\left(20^{\circ} \mathrm{C}\right)\end{array}$} & \multicolumn{2}{|c|}{$\mathrm{A} 5[\%]$} & \multicolumn{2}{|c|}{$\mathrm{Rm}\left[\mathrm{N} / \mathrm{mm}^{2}\right]$} \\
\hline & & Steel & Steel & Steel & Steel & Steel & Steel & Steel & Steel & Steel & Steel & Steel 1 & Steel 2 \\
\hline & & 1 & 2 & 1 & 2 & 1 & 2 & 1 & 2 & 1 & 2 & & \\
\hline (1) & 1000 & 74 & 78 & 124 & 165 & 4.67 & 5.03 & 155.5 & 93.5 & 43.5 & 35 & 391 & 549 \\
\hline (1) & 950 & 74.3 & 78.14 & 128 & 165 & 5.81 & 6.2 & 149.5 & 94 & 39.5 & 34.2 & 399 & 547 \\
\hline (1) & 900 & 76 & $73.7^{-}$ & 128 & 164.5 & 6.06 & 6.82 & 149.5 & 88 & 43 & 32 & 400 & 551 \\
\hline (1) & 850 & 77.4 & 77 & 134 & 181.5 & 7.55 & 7.35 & 148 & 89 & 37.3 & 32.5 & 398 & 562 \\
\hline (2) & 1000 & 73.8 & 77.8 & 131 & 172 & 3.63 & 3.69 & 111 & 96 & 38 & 35.3 & 388 & 558 \\
\hline (2) & 950 & 77.5 & $79.3^{-}$ & $140^{-}$ & 162 & 3.73 & 3.88 & 80.5 & 86 & 40.2 & 34 & 398 & 548 \\
\hline (2) & 900 & 71.8 & 77.8 & 125 & 160 & 4.23 & 4.15 & 70.5 & 90 & 39.5 & 36.8 & 393 & 534 \\
\hline (2) & 850 & 77 & 78.5 & 152 & 162.5 & 4.37 & 4.61 & 63.5 & 91 & 41.8 & 35.8 & 410.2 & 562 \\
\hline (3) & 1000 & 73.7 & 76.8 & 119 & 183 & 17.82 & 19.6 & 116.5 & 98 & 43.8 & 33.8 & 415.4 & 542 \\
\hline (3) & 950 & 77.4 & 76.6 & 139 & 178 & 18.6 & 20.21 & 178.5 & 96 & 37 & 34.8 & 412 & 549 \\
\hline (3) & 900 & 75.2 & 72.6 & 140 & $175^{-}$ & 19.13 & 20.95 & 177.5 & 98 & 40.3 & 33.8 & 402 & 555 \\
\hline (3) & 850 & 78.14 & 77.8 & 139 & 184 & 19.76 & 21.84 & 167.5 & 90 & 41.2 & 33.2 & 400.16 & $551^{-}$ \\
\hline
\end{tabular}



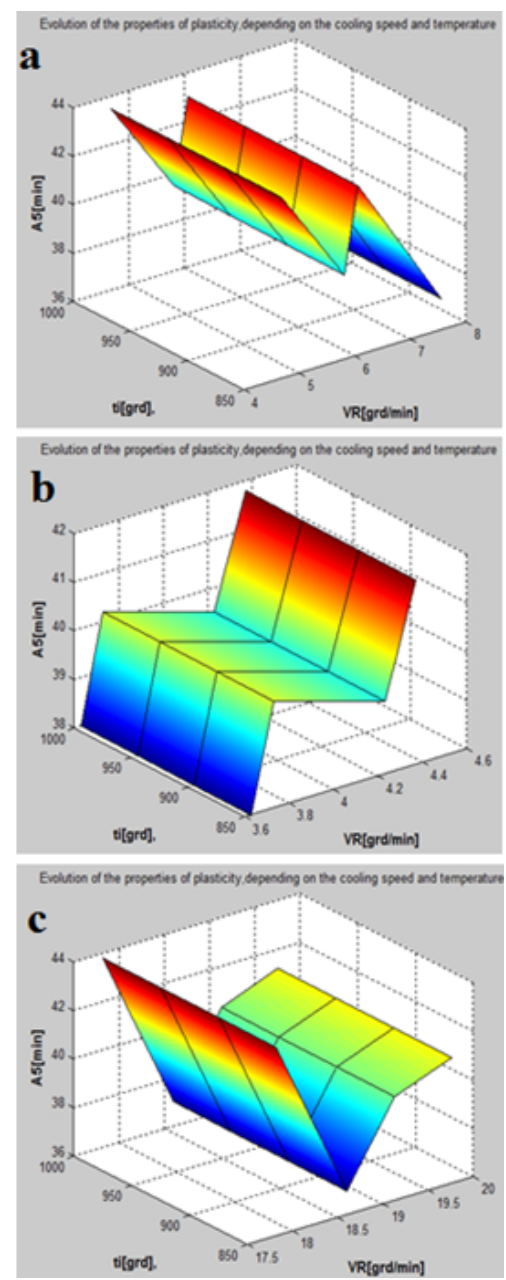

Fig.2. The evolution of the Steel 1 elongation at break (A5,[\%]) vs. cooling speed (VR) and temperature

(ti), for: a - cooling in normal conditions; $b$ - cooling in metallic box; $c$ - for cooling in jet of air.

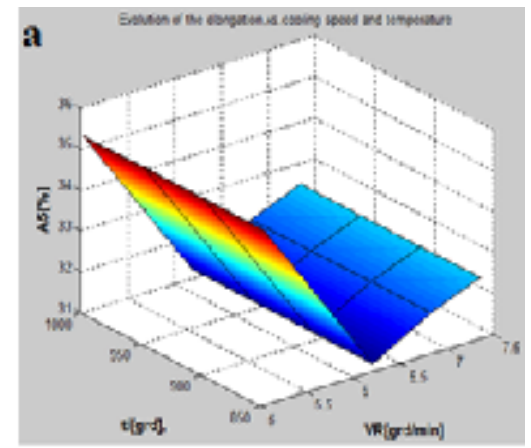

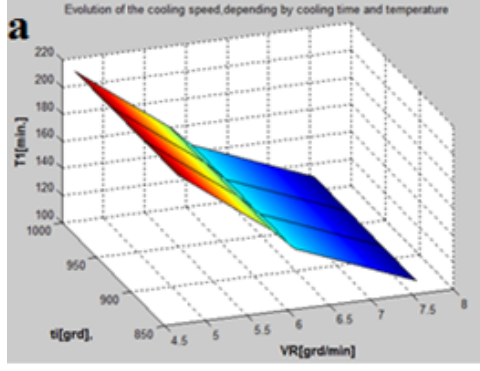
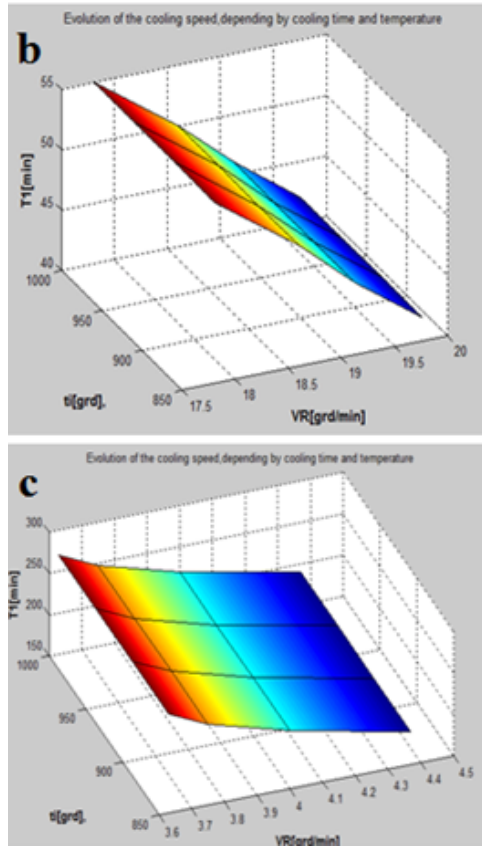

Fig. 3. The evolution for Steel 1 of the cooling speed (VR), versus cooling time (T1) and temperature (ti), corresponding to: a - normal conditions; $b$ - cooling in jet air; $c$ - cooling in metallic box

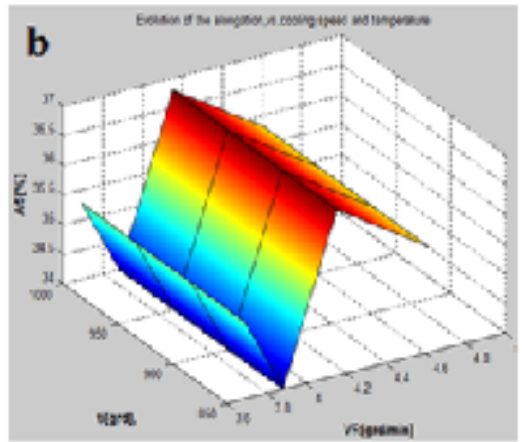

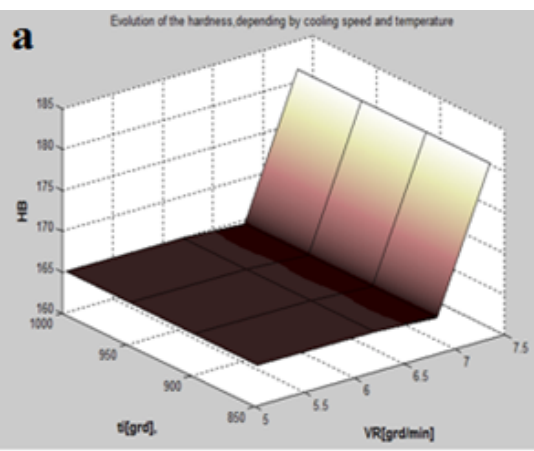
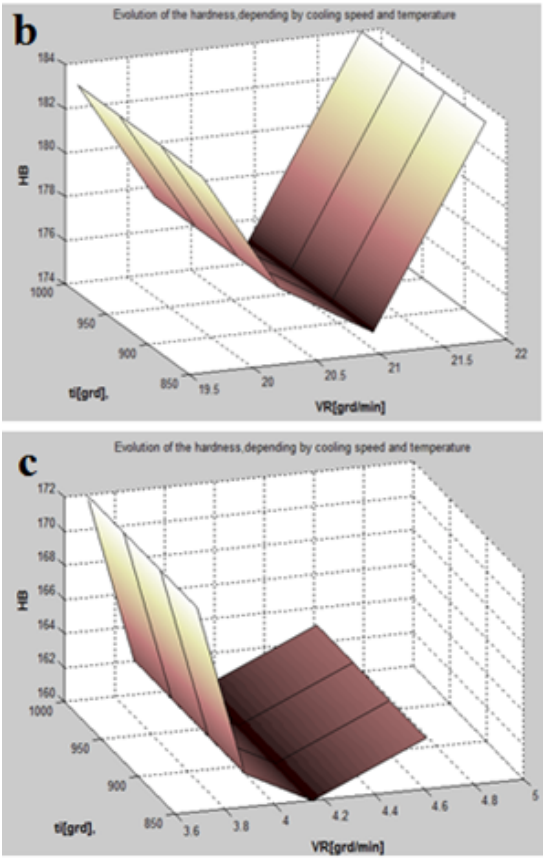

Fig.4.The evolution of the Steel 2 hardness

(HB) vs. cooling speed (VR) and temperature, Corresponding to: a- normal cooling conditions; $b$ - cooling in jet of air; $c$ - cooling in metallic box

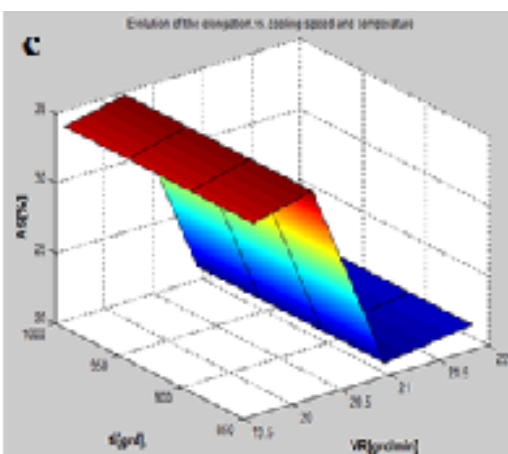

Fig.5. The evolution for Steel 2 of the elongation at break (A5,[\%]) vs. cooling speed (VR) and temperature (ti), for: a - cooling in normal conditions; $b$ - cooling in metallic box; $c$ - cooling in jet of air
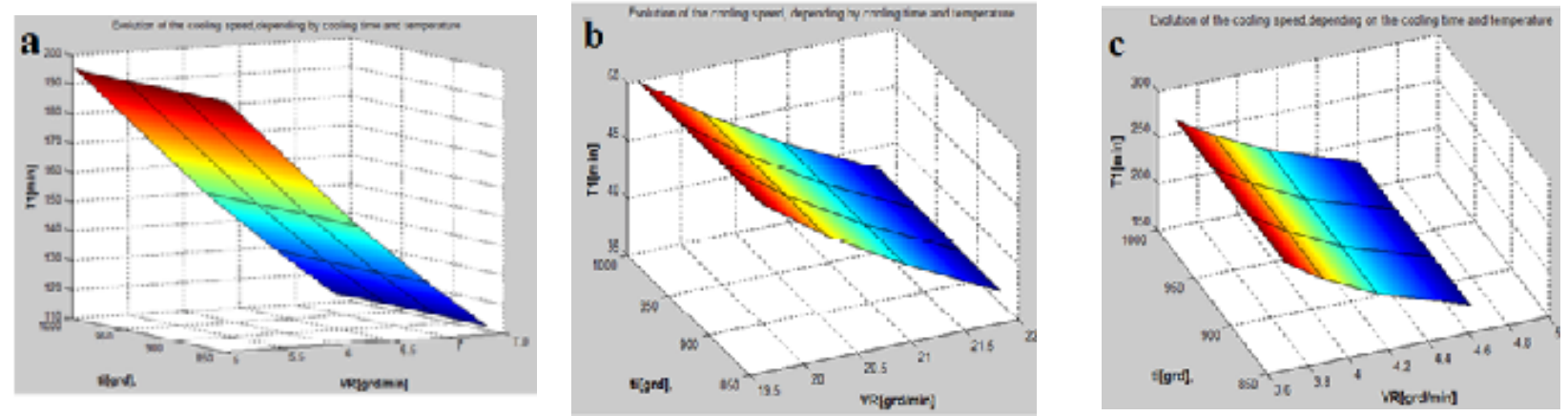

Fig. 6. The evolution for Steel 2 of the cooling speed (VR), versus cooling time (T1) and temperature ( $t$ ), corresponding to: a - normal conditions; b - cooling in jet of air; $c$ - cooling in metallic box, 

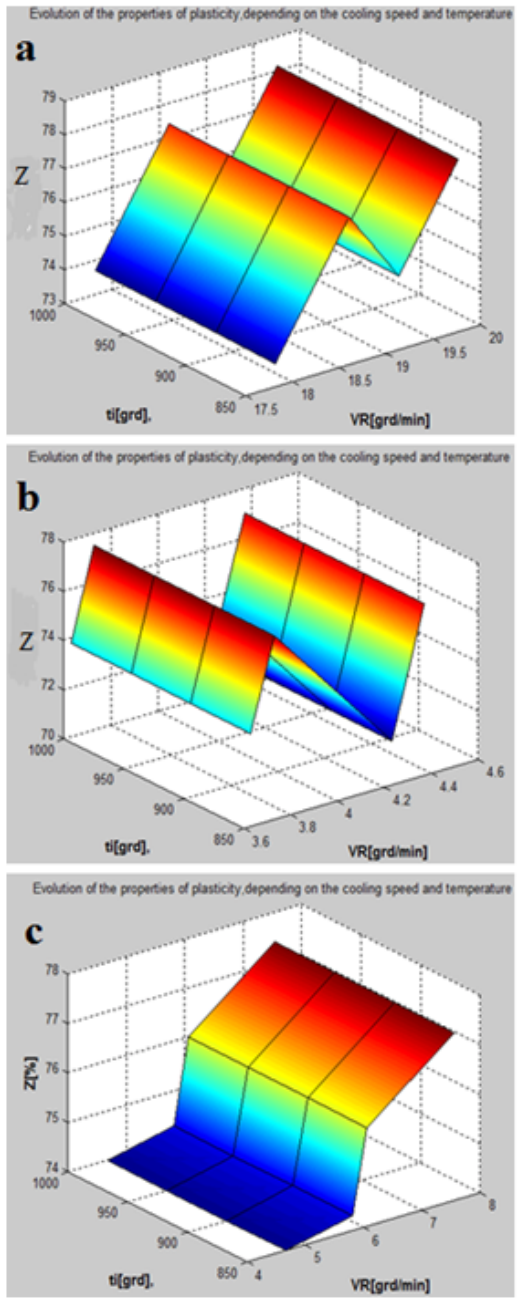

Fig. 7. The evolution for Steel 1 of the Thinning (Z,[\%]) vs. cooling speed (VR) and temperature (ti), for: a - cooling in jet of air; b - cooling in metallic box; c- cooling in normal conditions

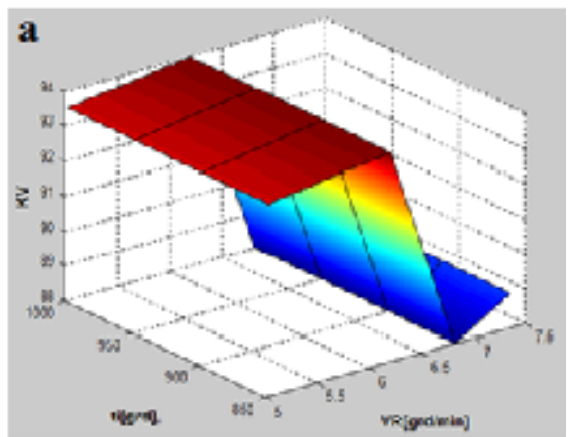

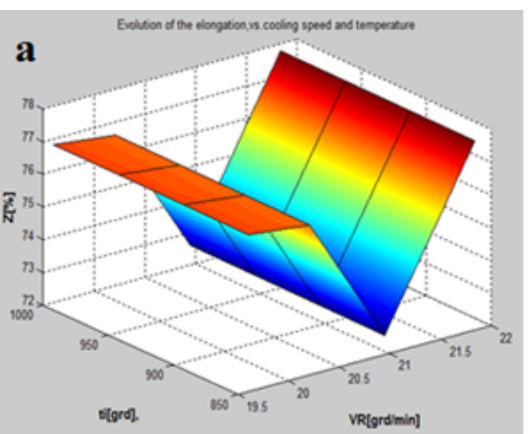
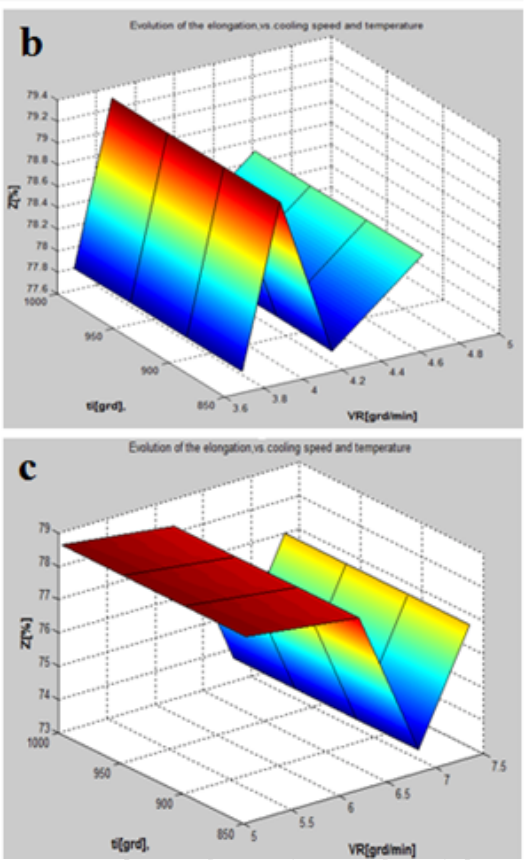

Fig.8. The evolution for Steel 2 of the Thinning (Z,[\%]) vs. cooling speed (VR) and temperature (ti), for: $a$ - cooling in jet of air; b - cooling in metallic box; c - cooling in normal conditions

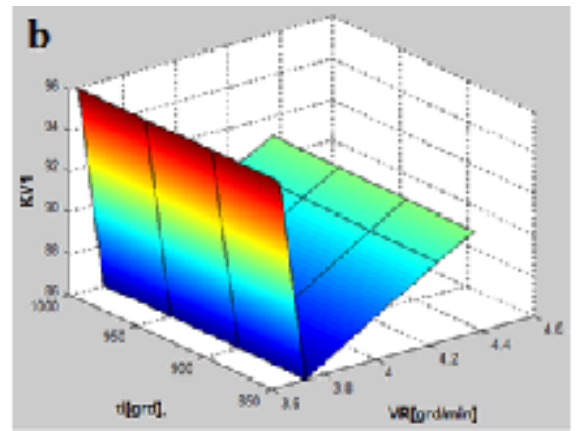

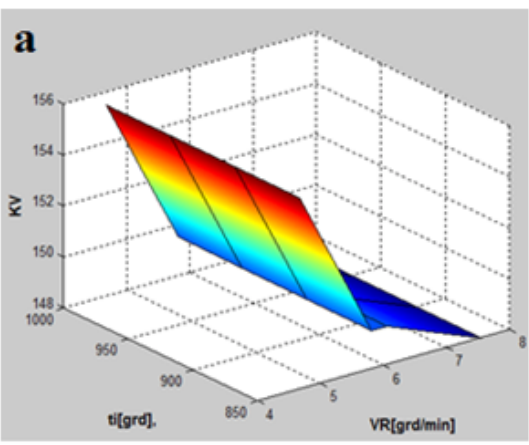
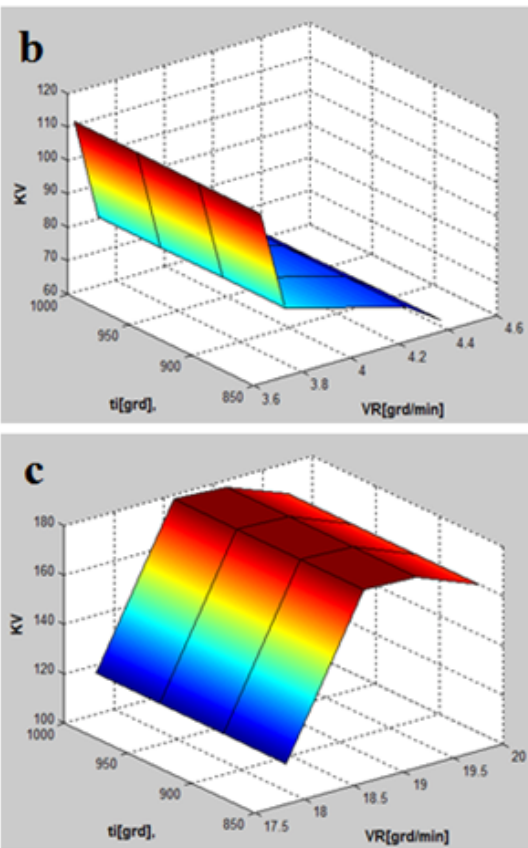

Fig. 9. Evolution of the resilience $\mathrm{KV}\left(+20^{\circ} \mathrm{C}\right)$ corresponding to Steel 1 , depending on the cooling speed, for: a - cooling in normal conditions; $b$ - cooling in metallic box; $c$ - cooling in jet of air.

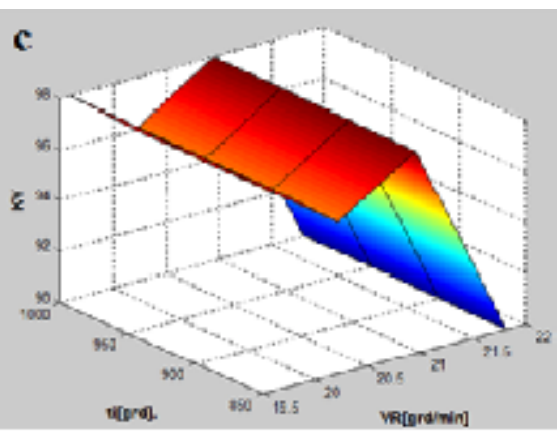

Fig. 10. Evolution of the resilience $\mathrm{KV}\left(+20^{\circ} \mathrm{C}\right)$ corresponding to Steel 2, depending on the cooling speed, for: a - cooling in normal conditions; $b$ - cooling in metallic box; $c$ - cooling in jet of air

In figures $3 a$ to $3 c$ was represented the evolution of the cooling speed versus cooling time, depending on the cooling medium for Steel 1 . In figures $6 a$ to $6 c$ was represented the evolution of the cooling speed versus cooling time, depending on the cooling medium for Steel 2.

In figures $7 a$ to $7 c$ and in figures $8 a$ to $8 c$ were represented the evolutions of the plasticity characteristic, for example, the Thinning (Z [\%]) evolution versus the cooling speed (VR) and initial temperature (ti), for Steel 1 and Steel 2 .

In figures $9 \mathrm{a}$ to $9 \mathrm{c}$ were represented the evolutions of the resilience $K V\left(+20^{\circ} \mathrm{C}\right)$ corresponding to Steel 1 and in figures 10a to $10 \mathrm{c}$ were represented the evolutions of the resilience $K V\left(+20^{\circ} \mathrm{C}\right)$ corresponding to Steel 2 .

\section{Conclusions}

The highest resilience had been obtained in the case of Steel 1, corresponding to the cooling in jet of air. Resilience decreases more in the case of the cooling in metallic box. Cooling speed had a very important increased value in the case of cooling in jet of air.

The hardness increases very much in the case of the cooling in jet of air and in metallic box, for both of steels grades.

It can be observed that in the case of the steel with a higher quantity of Carbon (Steel 2) than the other steel, the hardness has better values comparing with the other alloy (Steel 1). 
If the content of Carbon increases in the structure of the steel, some of plasticity properties increase, depending on the cooling regime.

The experimental program shown that the plasticity characteristics differ appreciably according to process parameters (for example, VR).

\section{References}

1.PAPADATU, C.P., SANDU, A.V., BORDEI, M, SANDU, I.G., Rev. Chim.(Bucharest), 67 no. 11, 2016, p. 2306.

2.DZIEDZIC, M., TURCZYN, S., Rolling of advanced High Strength Steels for automotive industry, Proceeding of International Conference on Metallurgy and Metals, METAL 2012, Brno, Czech Republic, 2012. 3.MEJ ÍA, I., BEDOLLA-JACUINDE, A., MALDONADO, C., BRERA, J.M., Mater. Sci. Eng. A, 528, no. 12, 2011, p. 4133.

4.LIU, Y.G., Li, M.Q., LUO, J., Mater. Sci. Eng. A, 574, 2013, p. 1. 5.PAPADATU, C.P. Studies and researches regarding the influence of the cooling speed on the properties and the structures of steels, Graduated Project, Dunarea de J os University, Galati, Romania, 1994. 6.VAN DO, V.N., Procedia Engineering, 142, 2016, p. 26.

7.MAKHECHA, D.P., GANAPATHI, M., PATEL, B.P., Compos. Struct., 51, no. 3, 2001, p. 221.

8.MORADI, S., MANSOURI, M.H., Steel Compos. Struct., Int. J., 12(2), 2012, pp. 129-147

9.TOPAL, U., Steel Compos. Struct. Int. J., 13, no. 3, 2012, p.207. 10.SANDU, A.V., CIOMAGA, A., NEMTOI, C., BEJINARIU, C., SANDU, I., J ournal of Optoelectronics and Advanced Materials, 14, no. 7-8, 2012, p. 704.

11.NEJ NERU, C., VIZUREANU, P., SANDU, A.V., GRECU, A., CIMPOESU, N., Rev. Chim. (Bucharest), 65, no. 2, 2014, p. 194.

12.PAPADATU, C.P., SANDU, A.V., BORDEI, M., SANDU, I.G., Rev. Chim. (Bucharest), 68, no. 4, 2017, p. 675.

13.SANDU, A.V., CODDET, C., BEJ INARIU, C., J. Optoelectron. Adv. M., 14, no. 7-8, 2012, p. 699.
14.PAPADATU, C.P., SANDU, A.V., BORDEI, M., SANDU, I.G., Rev. Chim. (Bucharest), 68, no. 10, 2017, p. 2329.

15.PAPADATU, C.P., SANDU, I.G., BORDEI, M., NABIALEK, M., SANDU, A.V., Mat. Plast., 53, no. 4, 2016, p. 771.

16.SANDU, A.V., CIOMAGA, A. NEMTOI, G., ABDULLAH, M.M.A., SANDU, I., Instrumentation Science \& Technology, 43, 2015, p. 545.

17.SANDU, A. V., CIOMAGA, A., NEMTOI, G., BEJ INARIU, C., SANDU, I., Microsc. Res. Tech., 75, 2012, p. 1711.

18.SANDU, A.V., BEJ INARIU, C., NEMTOI, G., SANDU, I.G., VIZUREANU, P., IONITA, I., BACIU, C., Rev. Chim.(Bucharest), 64 no. 8, 2013, p. 825.

19.UNGUREANU, C., GRAUR, A., Advances In Electrical And Computer Engineering, 15, no. 4, 2015, p. 69.

20.BERE, P., BERCE, P., NEMES, O., Composites Part B-Engineering, 43, no. 5, 2012, p. 2237.

21.PETRISOR, S.M., BARSAN, G., Proceedings of SPIE, 9067, 2013, article $90671 \mathrm{M}$

22.***ASTM E8/E8M, Standard Test Methods for Tension Testing of Metallic Materials: https://www.astm.org/Standards/E8.htm.

23.PAPADATU, C.-P., Researches on improving the properties and reliability of some steel grades used for manufacturing metallurgical equipment, PhD. Thesis, Dunarea de Jos University, 2006, Galati, Romania

24.***ASTM E9-21,Standard Test Methods for Elevated Temperature Tension Tests of Metallic Materials: https://www.astm.org/Standards/ E21.htm

25.***ASTM: E23-07ae1, Standard Test Methods for Notched Bar Impact Testing of Metallic Materials: https://www.astm.org/Standards/E23.htm 26.GERU, N., Analysis of the Structure of the Metallic Materials, 1991, Technical Publishing House, Bucuresti Romania

27.***ASTM E3-11, Standard Guide for Preparation of Metallographic Specimens: https://www.astm.org/Standards/E3.htm

Manuscript received: 28.07.2017 